\title{
Study of tribological properties of natural rubber containing carbon nanotubes and carbon black as hybrid fillers
}

Evghenii Harea, $1 \square$

Emailharea@cps.utb.cz

Radek Stoček, 1

Emailstocek@utb.cz

Liudmyla Storozhuk, 2

Emailstorozhukl@ukr.net

Yurii Sementsov, 2

Emailysementsov@ukr.net

Nikolai Kartel, 2

Emailnikar@kartel.kiev.ua

1 Centre of Polymer Systems, Tomas Bata University in Zlín, Tomas Bata Street, 5678, Zlín, Czech Republic

2 Chuiko Institute of Surface Chemistry, National Academy of Science of Ukraine, 17 General Naumov Street, Kiev, 03164 Ukraine

Received: 31 December 2017 / Accepted: 25 April 2018

\section{Abstract}

Dry friction and wear properties of natural rubber (NR), containing multi-walled carbon nanotubes (MWCNT) and carbon black (CB), were investigated. Natural rubber (NR)-based composites containing all common additives and curatives, and a fixed amount (30 phr-parts per 100 rubber by weight) of hybrid fillers $\left(\mathrm{MWCNT}_{x}+\mathrm{CB}_{30-x}\right)$ were prepared by simple mixing procedure and tested. The main goal was to study the behaviours of composites at different tribological 
testing conditions, such as friction speed and normal load. It was found that with an increase of concentration of MWCNT from $x=0 \mathrm{phr}$ to $x=5 \mathrm{phr}$ in studied composites, there was a decrease in the coefficient of friction (COF) with no significant change in wear in the framework of each used combination of testing parameters. Generally, higher friction speed at certain normal force led to the increase of $\mathrm{COF}$ of all the samples and wear reflected deliberate value fluctuation. Also, it was established that considerable growth of wear and unexpected reducing of friction coefficient ensued from increasing of applied load for every fixed sliding speed.

\section{Keywords}

Carbon nanotubes

Tribology

Natural rubber composites

Hybrid fillers

\section{Introduction}

In the scientific world, the last few decades can be named as "carbon era". Starting with fullerene in 1985 (Kroto et al. 1985), investigations were continued on nanotubes (Iijima 1991) and later on graphene layers (Geim 2009). Numerous articles were devoted to carbon nanotubes (CNTs) and materials filled with them. Due to ultimate properties of CNTs, materials filled with nanotubes show large improvement of mechanical and electrical parameters.

CNT-based polymer composite materials were developed for application in various industrial sectors due to their high durability, high strength and low weight. The conductivity, elasticity and toughness can also be significantly improved by the addition of nanotubes (Hwang et al. 2011). Besides the aforementioned properties, the heat stability, media stability, permeation behaviour and abrasion resistance are the requirements for elastomers doped with carbon nanotubes and compounded for technical and medical demands (Tegtmeier 2016). Commonly, CNTs are divided into two categories: a single-walled carbon nanotube (SWCNT) which consists of a single graphene cylinder and a multi-walled carbon nanotube (MWCNT) containing several concentric graphene cylinders.

Natural rubber (NR) filled with CNT was extensively studied for the development of flexible materials with enhanced electrical conductivity (Bokobza 2012; 
Nakaramontri 2017). Although numerous methods were used for composite preparation, the big challenge which still remained was the direction of achieving a homogenous distribution of CNT in the NR matrix. The problem of inhomogeneity was due to Van der Waals interactions between nanotubes which generated a tendency to form agglomerates (Nakaramontri 2017). To achieve better dispersion of CNTs in the NR matrix, various mixing procedures such as solution and latex mixing (Bokobza 2012), functionalizing CNT surfaces (Nakaramontri 2015), use of ionic liquid (Subramaniam 2013) and metal nanoparticles (Ma 2008) were attempted. All these methods are time consuming and quite expensive. On the other hand, a relatively simple and functioning method was reported by Nakaramontri (2017). Thus, the optimal state of filler dispersion in the NR matrix was gained by the preparation of NR composites with hybrid CNT and carbon black (CB) fillers. Furthermore, CNT are linked by CB agglomerates and create an improved conductive network inside of rubber matrix. The elastomer with hybrid nanofillers seems to be a promising material for flexible electronics. In the real electronic device, the flexible part is usually in contact with rigid metallic conductors. This is why the longevity and correct functionality of such a gadget will depend on tribological properties of elastomer-metal contact.

The present work is dedicated to the preparation of NR composites with hybrid MWCNT and CB fillers via simple mixing method (Nakaramontri 2017) and investigation of their mechanical properties. The various batches prepared are shown as sample composition in Table 1. Particular attention is paid to the frictional properties of elastomer-metal interaction, characterised by a friction coefficient (COF) and wear as a function of sliding speed, applied load and hybrid fillers concentration. Although many articles described the benefits of CNT for the tribological properties of various composite materials (Reinert 2016; Hentour 2016), the elastomers filled with nanotubes were investigated insufficiently, and the variation of wear and COF with concentration of CNT fillers in the rubber matrix were still subjected to questions (Felhös and Karger-Kocsis 2011). Moreover, it is believed that there is no reported study on frictional behaviours of rubbers filled with CNT and CB hybrid fillers.

\section{Table 1}

Sample composition

\begin{tabular}{|l|l|l|l|l|l|}
\hline & NR0 & NR0.5 & NR1 & NR3 & NR5 \\
\hline NR (phr) & 100 & 100 & 100 & 100 & 100 \\
\hline
\end{tabular}




\begin{tabular}{|l|l|l|l|l|l|}
\hline & NR0 & NR0.5 & NR1 & NR3 & NR5 \\
\hline CNT (phr) & 0 & 0.5 & 1 & 3 & 5 \\
\hline CB (phr) & 30 & 29.5 & 29 & 27 & 25 \\
\hline
\end{tabular}

\section{Experimental}

\section{Materials}

Natural rubber used in this research was supplied by the Astlett Rubber Inc (type SMR $20 \mathrm{CV} / \mathrm{BP} 1)$. Sulphur was used as the curing agent, whereas zinc oxide ( $\mathrm{ZnO})$ and stearic acid were used as activators. Sulphur, zinc oxide, and stearic acid were supplied by Sigma-Aldrich ${ }^{\circledR}$. Carbon black of the type N220 was used as filler. CBS ( $N$-cyclohexyl-2-benzo-thiazole-sulfenamide) was employed as curing accelerator. The complete composition of the compounds is listed in Table 2.

\section{Table 2}

Rubber composition

\begin{tabular}{|c|c|c|c|c|c|c|c|}
\hline & NR & CNT & $\begin{array}{l}\text { Carbon } \\
\text { black }\end{array}$ & CBS & Sulphur & $\mathrm{ZnO}$ & $\begin{array}{l}\text { Stearic } \\
\text { acid }\end{array}$ \\
\hline & \multicolumn{7}{|c|}{ Content in phr ${ }^{a}$} \\
\hline $\begin{array}{l}\mathrm{NR}\left(\mathrm{CNT}_{x}+\right. \\
\left.\mathrm{CB}_{30-x}\right)\end{array}$ & 100 & $x^{\mathrm{b}}$ & $30-x$ & 2.5 & 1.7 & 3 & 1 \\
\hline \multicolumn{8}{|c|}{$\begin{array}{l}\text { aphr-the compound ingredients are given as parts per } 100 \text { by weight of the rubber } \\
\text { polymer }\end{array}$} \\
\hline \multicolumn{8}{|c|}{$\mathrm{b}_{x}=0.0,0.5,1.0,3.0,5.0$} \\
\hline
\end{tabular}

Multi-walled carbon nanotubes (Fig. 1) with average diameter of 10-20 nm obtained by catalytic pyrolysis described in Yanchenko et al. (2004) were provided by Chuiko Institute of Surface Chemistry, National Academy of Sciences of Ukraine.

\section{Fig. 1}

TEM of MWCNT 


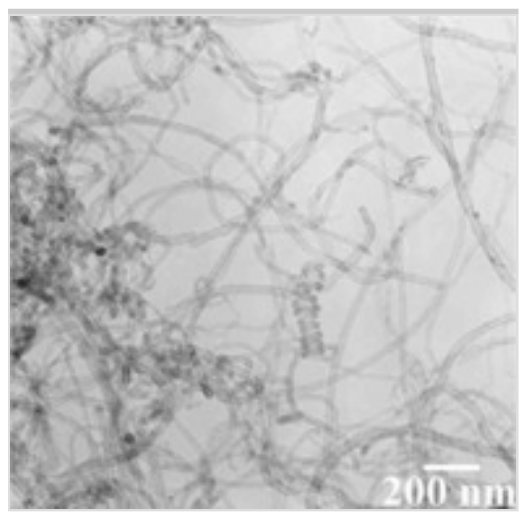

\section{Rubber compounding}

The rubber compounds based on NR filled with CB and hybrid CB + MWCNT fillers were mixed in a Brabender Plastograph. The compounding was performed at $60{ }^{\circ} \mathrm{C}$, at $60 \mathrm{rpm}$ and at a fill factor of $80 \%$. The chemicals in proportion listed in Table 1 were successively added as follows (Nakaramontri 2017): elastomer was mixed for $3 \mathrm{~min}$ followed by mixing of the hybrid fillers for $2 \mathrm{~min}$. $\mathrm{ZnO}$ and stearic acid activators were consecutively added and mixed. Finally, CBS and Sulphur were added in batches, and the total mixing time was 9 min.

After $24 \mathrm{~h}$ conditioning at an ambient temperature $20^{\circ} \mathrm{C}$ and a relative humidity of $40 \%$, the blends were moulded into $125 \times 125 \times 2 \mathrm{~mm}$ sheets and cured in an electrically heated hydraulic press at $160{ }^{\circ} \mathrm{C}$ under $200 \mathrm{kN}$ force in accordance with the optimum curing time established using a moving die rheometer (MDR 3000, Montech).

\section{Testing}

Dry friction tests were performed using a Bruker Universal Mechanical Tester (UMT) Tribolab in a linear ball-on-flat mode at room temperature in air. The relative humidity was $40 \pm 5 \%$. An 8 -mm diameter ball, made of stainless steel, was slid against a flat sample in reciprocating mode under constant load of 1 and $2 \mathrm{~N}$. The ball pass was 600 cycles at 2, 10 and $20 \mathrm{~mm} / \mathrm{s}$ sliding speed.

The determination of hardness was done using a BAREISS HP-A-Shore A durometer (method SHORE, ISO 868). This method measures the penetration of a specially shaped steel rod after a fixed time which in the present study was $3 \mathrm{~s}$.

Frequently, the hardness serves as a parameter which complements the comprehension of friction behaviour (Harea et al. 2017). 
Uniaxial tensile tests were performed on Testometric MT350 testing machine.

The width of friction tracks were measured by a Leica DVM2500 optical microscope.

Studies on the arrangement of MWCNT fillers on the surface of the samples and also inside of the bulk materials were carried out using a scanning electron microscope (SEM), model Nova NanoSEM 450 (FEI) with Schottky field emission electron source. To visualise nanotubes, selective chemical treatment of rubber in toluene was done. It is important to mention that chemical treatment of vulcanised samples was unsuccessful. The small micron-size particles of cured rubber containing MWCNT were detached from the etched surface in such a way that the remaining nanotubes did not illustrate the real state of the fillers. Appropriate results were obtained from uncured composite slabs which were prepared using similar conditions to those applied earlier for vulcanised samples except the temperature which in this case remained equal to the room temperature. Composition NR5 containing maximum amount ( $5 \mathrm{phr}$ ) of MWCNT was pressed into sheet of $2 \mathrm{~mm}$ thickness, later two samples of $10 \times 10 \times 2 \mathrm{~mm}^{3}$ and $10 \times 10 \times$ $1 \mathrm{~mm}^{3}$ were cut. Therefore, two experimental surfaces were obtained: an exterior surface and an interior surface as a central cross-section of studied specimens. The next steps were chemical treatment in toluene for $20 \mathrm{~min}$ at room temperature followed by drying at $50{ }^{\circ} \mathrm{C}$ in vacuum, for $5 \mathrm{~h}$. It is believed that the method of selective chemical treatment of rubber used for visualisation of arrangement of CNT fillers has been used for the first time. Of course, the method may be improved by removal of residual etched material from analysed surfaces.

\section{Results and discussion}

During the cyclic friction process, roughness of friction track, contact temperature debris formation and other parameters produced a certain steady state value, and the values of the friction coefficient remained almost constant for certain frictional conditions. The similar trend was mentioned by Felhös and Karger-Kocsis (2011) and Nuruzzaman and Chowdhury (2012). The time dependence of the COF during the reciprocated ball-on-flat tests showed almost stable value after 100 sliding cycles (Fig. 2) for all investigated samples at definite sliding speed and load which are operative frictional variables in the present work.

\section{Fig. 2}


Friction coefficient evolution vs sliding cycles and speed. Quantity of MWCNT: a, b $-0 \mathrm{phr}, \mathbf{c}, \mathbf{d}-0.5 \mathrm{phr}, \mathbf{e}, \mathbf{f}-1.0 \mathrm{phr}, \mathbf{g}, \mathbf{h}-3.0 \mathrm{phr}, \mathbf{i}, \mathbf{j}-5.0 \mathrm{phr}$. Applied normal force: $\mathbf{a}, \mathbf{c}, \mathbf{e}, \mathbf{g}, \mathbf{i}-1 \mathrm{~N} ; \mathbf{b}, \mathbf{d}, \mathbf{f}, \mathbf{h}, \mathbf{j}-2 \mathrm{~N}$

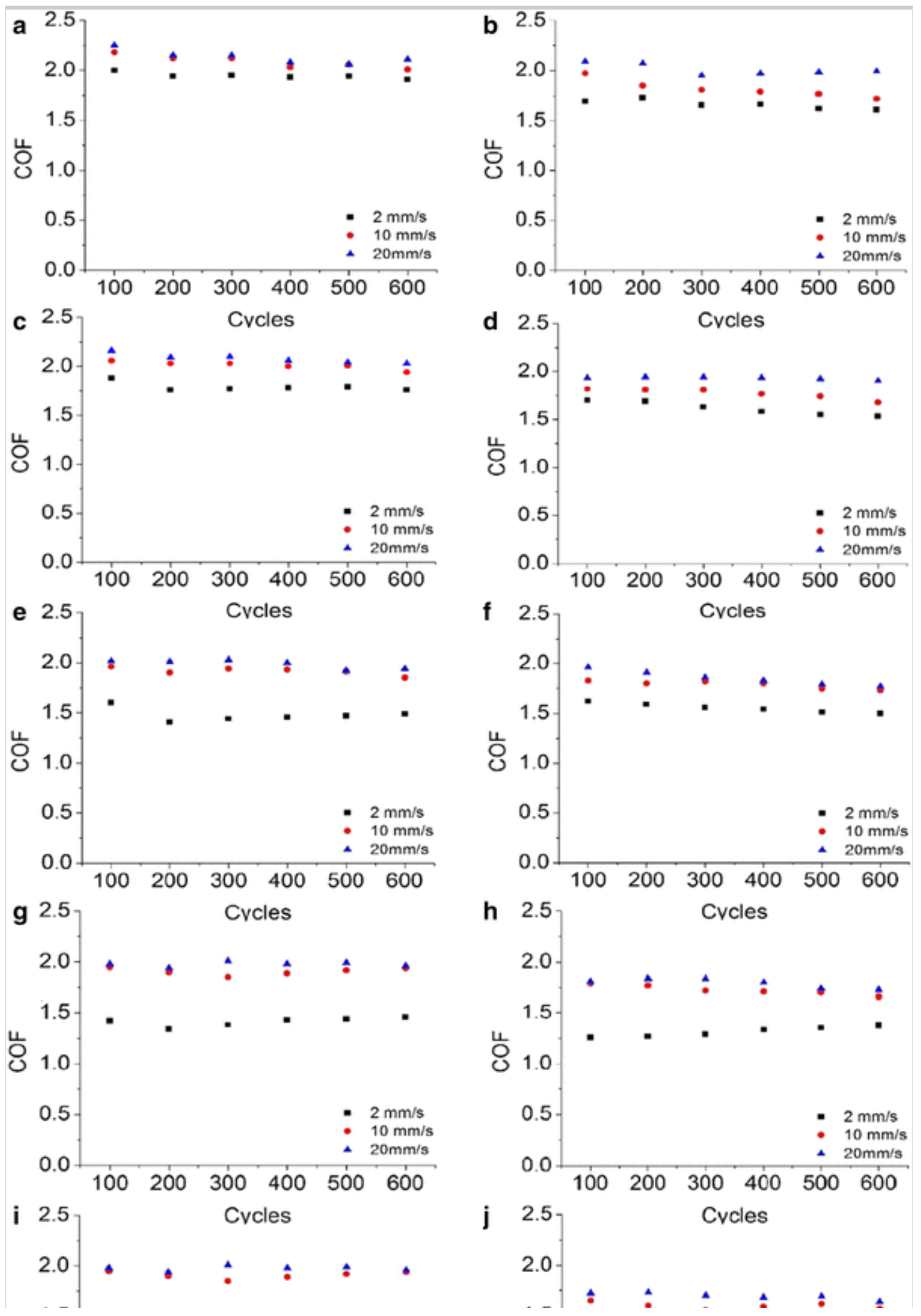




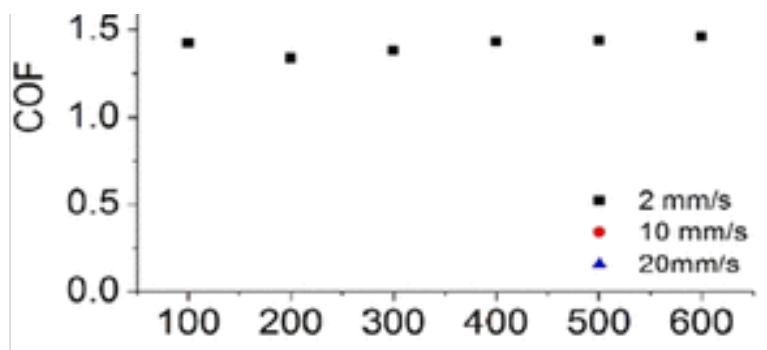

Crcles

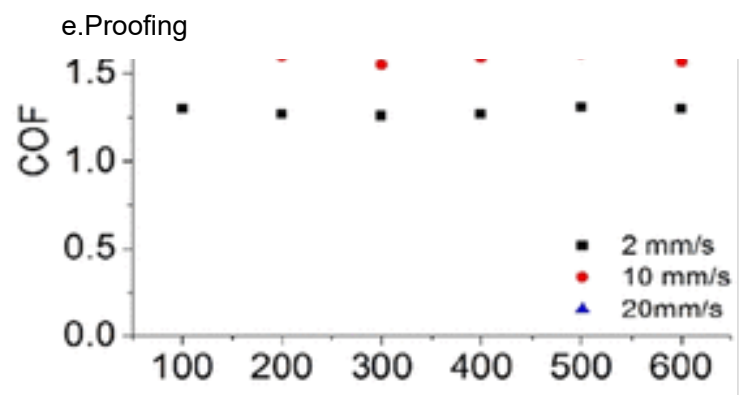

Crcles

The mean values of steady state regions (from 100 to 600 cycles) were calculated to examine the COF dependence on CNT concentration, ball sliding speed and applied load (Fig. 3).

\section{Fig. 3}

The mean value of COF as a function of MWCNT concentration, friction speed and applied normal force

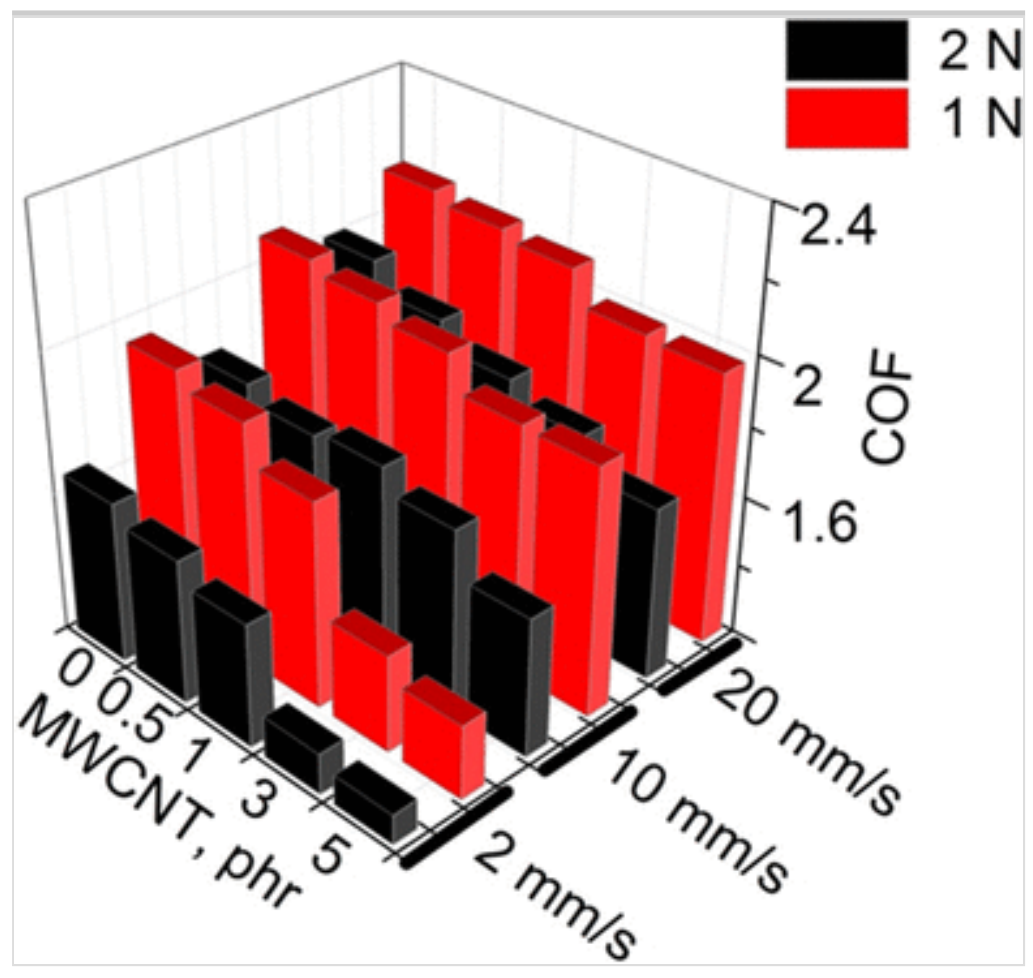

The increase of the concentration of MWCNT fillers in NR matrix consequently reduced the COF. The minimum COF was obtained for $5 \mathrm{phr}$ of MWCNT for all applied friction conditions. The reason for this significant improvement of frictional behaviour can be due to the released MWCNT from the worn surface which served as a solid lubricant between the sliding steel ball and flat rubber surface. 
Commonly, load setting and the speed in ball-on-plate reciprocating test play an important role in obtained frictional properties of materials. In the present study, when the load was increased from 1 to $2 \mathrm{~N}$, the friction coefficient of all investigated samples with nanotubes as well as without nanotubes exhibited a descending trend. The explanation of this effect derived from assumption proposed and proved by Schallamach (1952) lies in the fact that friction force is proportional to the true contact area between tested materials. On the other side, the true contact area is not directly proportional to the applied load (Fortunato 2017) because of roughness of surfaces which are in contact. For increment of pressure in contact between frictional surfaces, which do not exceed the value of Young's modulus of a tested material, the real contact area increases linearly. The next consequent increasing of normal force has a tendency to match the true contact area to the nominal one. Hence, the friction coefficient is not proportional with applied force and, according to the results obtained, it decreased as a function of applied load.

On the contrary, increasing the sliding speed from 2 to 10 and $20 \mathrm{~mm} / \mathrm{s}$ led to the rise in the friction coefficient value. Two main factors were responsible for such a behaviour: the total real contact area mentioned above was higher at lower driving speed (Maegawa et al. 2016), and the temperature in the contact spot rose for greater speeds and was responsible for increasing adhesion.

One more important parameter of any rubber composite is friction wear, and usually is controlled by a combination of several parameters which include the contact pressure, temperature, and sliding velocity (Reinert 2016). In contrast to the sliding wear of hard materials, elastomers involve complex wear mechanisms which are affected by the appearance of the characteristic abraded surface (Fig. 4a). In samples filled with MWCNT, besides undulated ground surface, the agglomerates of debris randomly covered the friction track. Wool-flock-like debris (Fig. 4b) was characteristic for all MWCNT-containing samples and was not found in nanotubefree samples (NR0).

\section{Fig. 4}

Optical microscopy images of friction tracks at $2 \mathrm{~N}$ load and $10 \mathrm{~mm} / \mathrm{s}$ friction speed: a sample NR0, and b sample NR5 

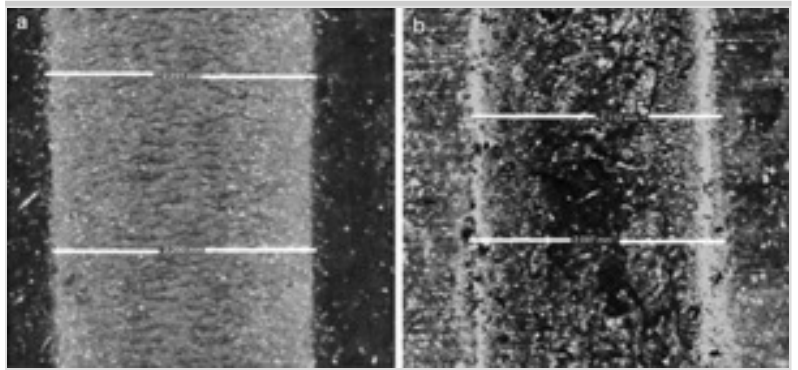

The determination of wear in rubber in ball-on-flat friction procedure is sometimes very difficult. Usually, the wear is defined like a volume of material which has lost its initial properties during friction process. The calculation of the real volume of such a material is difficult because besides detached material there is also the presence of abraded surface with unknown depth. In this case, the most suitable method was found to be the measurement of the track widths using optical microscopy. Obtained average results are presented in Fig. 5. The most valuable difference in wear of analysed samples was related to applied load variation. When normal force was increased from 1 to $2 \mathrm{~N}$ (Fig. 5a, b, respectively), the width of tracks rose up to $30 \%$. A sizeable difference in wear for different concentration of MWCNT was observed only for lowest sliding speed where it decreased by $8-9 \%$ between NR0 and NR5 for both applied loads. When friction speed was increased up to 10 and $20 \mathrm{~mm} / \mathrm{s}$, the presence of MWCNT did not change the wear significantly.

\section{Fig. 5}

Width of tracks as a function of MWCNT concentration and friction speed. Applied normal force: a $1 \mathrm{~N}, \mathbf{b} 2 \mathrm{~N}$

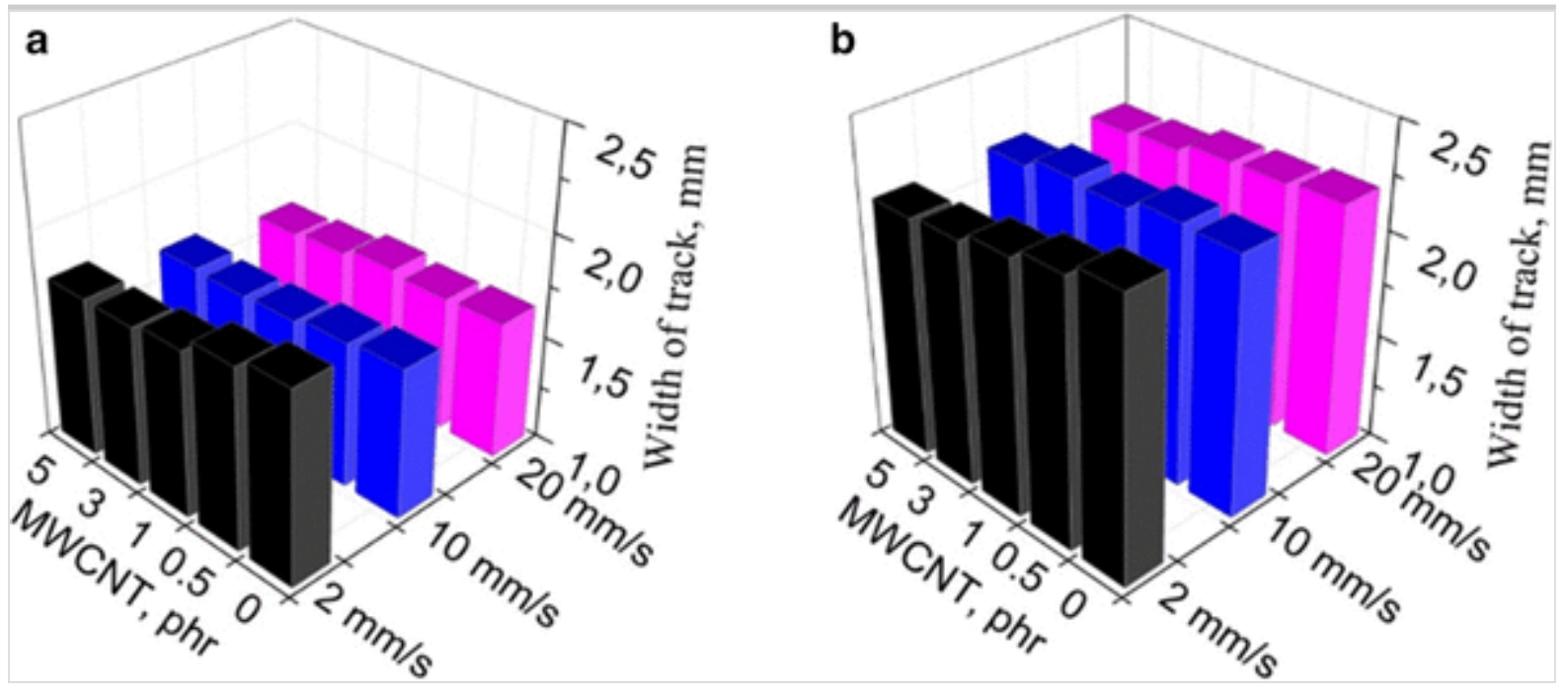


Commonly, the addition of fillers changes not only the frictional properties of materials but also all mechanical behaviours of investigated samples. Filler reinforcement of polymers usually increases the hardness, elastic modulus or stiffness and determination of relation between these parameters, and the tribological properties of materials are very important for further formulation of new compounds with desired behaviours. In the present work, it was of great interest to compare the "superficial" and "bulk" evolution of mechanical properties correlated to MWCNT concentration.

Tensile tests were performed on all studied samples according to standard ISO 37, type 2. The incorporation of nanotubes into NR led to the improvement of elastic modulus and stress at 100 and $200 \%$ of elongation (Table 3 ). The stress strength was equivalent to the stress at break and increased when MWCNT concentration increased up to $1 \%$, thereafter it decreased with further increase of the nanotube quantity.

\section{Table 3}

Tensile test results

\begin{tabular}{|c|c|c|c|c|c|c|}
\hline Sample & $\begin{array}{l}\text { Young's } \\
\text { modulus } \\
\text { (MPa) }\end{array}$ & $\begin{array}{l}\text { Stress @ } \\
\text { break } \\
\left(\mathbf{N} / \mathbf{m m}^{2}\right)\end{array}$ & $\begin{array}{l}\text { Force@ } \\
\text { break } \\
(\mathrm{N})\end{array}$ & $\begin{array}{l}\text { Elong.@ } \\
\text { break } \\
(\mathrm{mm})\end{array}$ & $\begin{array}{l}\text { Stress }_{100} \\
\left(\mathrm{~N} / \mathbf{m m}^{2}\right)\end{array}$ & $\begin{array}{l}\text { Stress }_{200} \\
\left(\mathrm{~N} / \mathrm{mm}^{2}\right)\end{array}$ \\
\hline NR0 & $1.33 \pm 0.08$ & $20.43 \pm 1.92$ & $\begin{array}{l}179.74 \pm \\
16.82\end{array}$ & $\begin{array}{l}194.89 \pm \\
16.54\end{array}$ & $\begin{array}{l}2.71 \pm \\
0.29\end{array}$ & $\begin{array}{l}4.42 \pm \\
0.20\end{array}$ \\
\hline NR0.5 & $1.45 \pm 0.08$ & $23.14 \pm 2.32$ & $\begin{array}{l}203.60 \pm \\
12.26\end{array}$ & $\begin{array}{l}218.29 \pm \\
13.23\end{array}$ & $\begin{array}{l}3.015 \pm \\
0.30\end{array}$ & $\begin{array}{l}4.72 \pm \\
0.16\end{array}$ \\
\hline NR1 & $1.51 \pm 0.07$ & $23.36 \pm 0.45$ & $\begin{array}{l}210.25 \pm \\
4.07\end{array}$ & $\begin{array}{l}222.01 \pm \\
4.53\end{array}$ & $\begin{array}{l}3.13 \pm \\
0.11\end{array}$ & $\begin{array}{l}4.93 \pm \\
0.07\end{array}$ \\
\hline NR3 & $1.94 \pm 0.04$ & $21.13 \pm 1.80$ & $\begin{array}{l}190.16 \pm \\
16.22\end{array}$ & $\begin{array}{l}198.18 \pm \\
15.97\end{array}$ & $\begin{array}{l}3.64 \pm \\
0.30\end{array}$ & $\begin{array}{l}5.4 \pm \\
0.28\end{array}$ \\
\hline NR5 & $2.04 \pm 0.08$ & $17.14 \pm 3.20$ & $\begin{array}{l}157.71 \pm \\
29.51\end{array}$ & $\begin{array}{l}157.84 \pm \\
27.88\end{array}$ & $\begin{array}{l}3.96 \pm \\
0.20\end{array}$ & $\begin{array}{l}5.91 \pm \\
0.16\end{array}$ \\
\hline
\end{tabular}

Such kind of relation is typical for CNT filled materials and is related according to (Bokobza 2012) to the formation of the nanotube agglomerates which create some failure points and lead to degradation of the mechanical properties of the materials. 
It is curious that superficial mechanical properties (friction coefficient, wear or hardness) varied progressively when MWCNT concentration was increased, and that was quite different compared to the stress strength parameters which had parabolic-like distribution and showed the maximum value for $1.3 \mathrm{phr}$ of MWCNT (according to the fitting curve in Fig. 6). The explanation can be the different rearrangement of MWCNT on the surfaces of sheet (Fig. 7a) compared to the arrangement of fillers in bulk material (Fig. 7b). Nanotubes progressively became flat-oriented in vicinity of sample surface. Therefore, a layer with higher density and planar orientation of fillers was created on the surface of press moulded materials. This layer was finally responsible for the tribological properties and hardness of the samples.

Fig. 6

The dependence of stress strength on MWCNT concentration: measured data and fitting curve

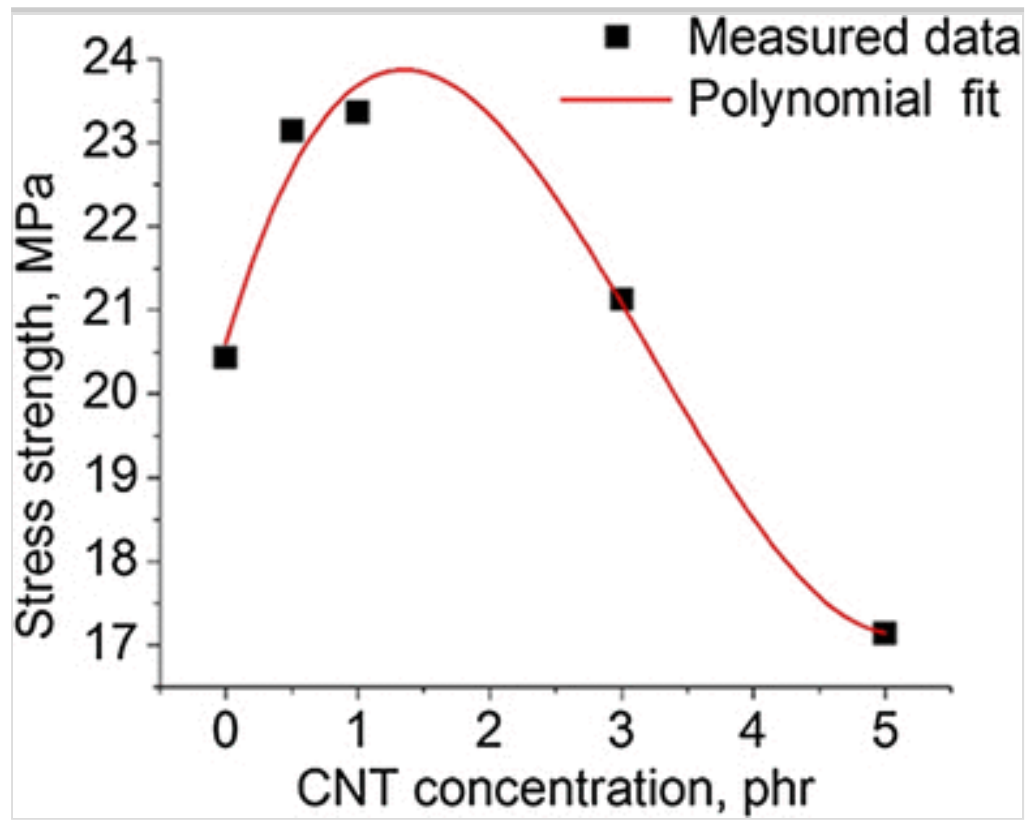

Fig. 7

Arrangement of MWCNT (composition NR5): a on the surface of pressed composite slab, and $\mathbf{b}$ in the middle of slab 


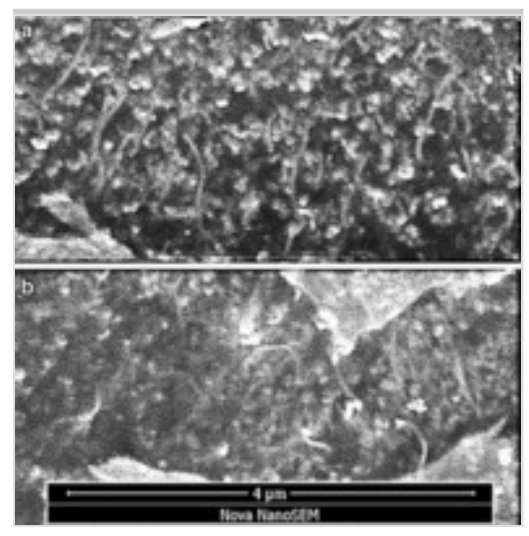

Hardness is the ability of a material to resist to scratching, perforation or deformation and usually expresses the deformability of materials under concentrated load action. Shore hardness is quantified by the penetration of a steel rod shaped like a truncated cone into surface and is related to the modulus of elasticity and viscoelastic properties of the material.

The addition of MWCNTs in NR matrix modifies physical and mechanical properties of the blends. The results of Shore A hardness measurements for investigated samples are depicted in Fig. 78. Hardness consequently increased with the MWCNT concentration, showing a minimum of 59 Shore degree for NR0 without nanotubes, and a maximum close to 65 obtained for sample NR5.

Therefore, from the experimental results, it can be summarised that the enhancement of tribological properties were mainly due to incorporation of MWCNT in polymer matrix. The CB contribution was basically to improve the distribution of the nanotubes during the mixing process and was supposed to have the same contribution for frictional behaviour of all tested composites. Both friction coefficient and wear in the experiments were mostly governed by debris formation. In samples doped with MWCNT, debris from detached nanotubes is impregnated with grated rubber particles. Nanotube reinforcement of elastomer matrix confirmed by hardness measurements decreased COF and slightly reduced the wear of composites for any taken configuration of operative frictional variables. Wool-like debris added their contribution through rolling and slipping inside of friction track. It was separately desirable to analyse effect of load on wear and COF which was remarkable. As it was mentioned, wear increased and COF decreased with load. High pressure formed in real contact area spots easily deteriorated the composite surface due to poor cohesion between nanotubes and vulcanised rubber and, therefore, produced debris. After certain number of cycles, the equilibrium occurred between debris formation and applied force, and the real contact area had a 
tendency to be more or less similar for definite normal force and friction speed, what was expressed through stabilisation of COF. At higher applied load, according to theory described in the introduction, the real contact area increased compared to the nominal area, pressure in contact spots decreased, but was still enough to generate debris until balance would be reached. In such a way higher applied load generates bigger wear, bigger amount of debris and decreased pressure in the contact spots. The last two statements explain the reduction in the COF for MWCNT filled samples. Nevertheless, influence of debris on real contact area could not fully explain the insignificant modification of wear compared with COF variation for different sliding speeds at fixed load. Here, the key role could have been played by the thermal increase of adhesion in the contact between abraded friction track, debris and steel ball (Fig. 8).

AQ1

Fig. 8

Shore A hardness of studied samples in dependence of MWCNT concentration

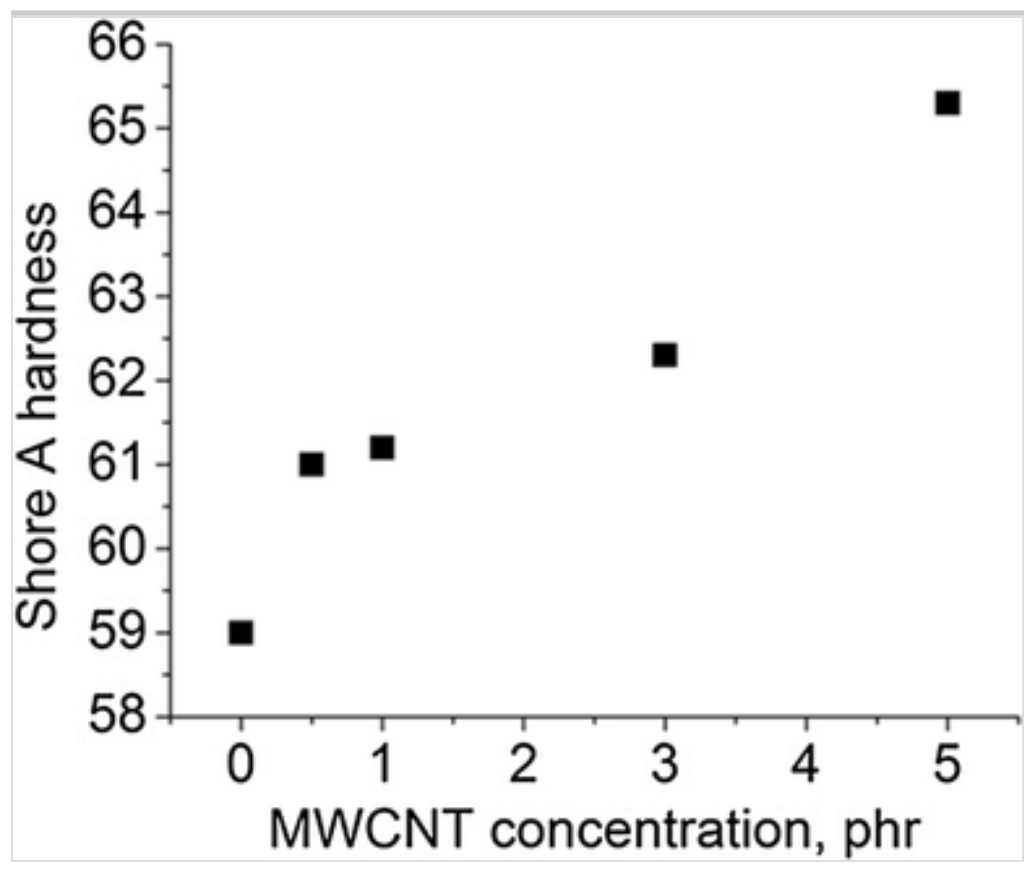

\section{Conclusions}

The production of NR-based composites with hybrid fillers (MWCNT + CB) by a simple mixing procedure showed promising mechanical results for low concentrations of MWCNT. Tensile strength results indicated reasonable homogeneity of MWCNT distribution up to $1.3 \mathrm{phr}$. Further increase of the 
concentration led to the agglomeration of nanotubes and reduced mechanical properties of bulk material.

The hardness and frictional properties were influenced mostly by interface behaviour of the studied composites. It was thought that superficial layer formation with higher concentration and orientation of nanotubes during the compression moulding was the reason behind such influence. That was the main reason to see reasonable trends in the variation of COF and wear with increasing of MWCNT concentration up to $5 \mathrm{phr}$.

Operative frictional variables, such as sliding speed and normal load, influenced the obtained results for all investigated samples. Generally, COF decreased with an increase MWCNT concentration. Higher normal load led to lower friction coefficient, and increasing sliding speed yielded increased COF. The most suitable explanation to the obtained result was the presence of detached MWCNT from rubber matrix inside of friction tracks.

Although the differences were not as significant as for COF values, increased MWCNT concentration in hybrid fillers produced lower wear of studied samples. Contrarily, the variation of normal applied load appreciably affected the wear volume: higher load resulted in higher wear.

\section{Publisher's Note}

Springer Nature remains neutral with regard to jurisdictional claims in published maps and institutional affiliations.

\section{Acknowledgements}

This article was written with the support of Operational Program Research and Development for Innovations co-funded by the European Regional Development Fund and national budget of the Czech Republic, within the framework of the project CPS — strengthening research capacity (reg. number:

CZ.1.05/2.1.00/19.0409) as well supported by the Ministry of Education, Youth and Sports of the Czech Republic_-Program NPU I (LO1504).

Compliance with ethical standards

Conflict of interest The authors declare that they have no competing interests.

\section{References}


Bokobza L (2012) Multiwall carbon nanotube-filled natural rubber: electrical and mechanical properties. Express Polym Lett BME-PT Hung 6(3):213-223. https://doi.org/10.3144/expresspolymlett.2012.24

Felhös D, Karger-Kocsis J (2011) Friction and wear of rubber nanocomposites containing layered silicates and carbon nanotubes. In: Mittal V, Kim JK, Pal K (eds) Recent advances in elastomeric nanocomposites. Springer, Berlin, pp 343379. https://doi.org/10.1007/978-3-642-15787-5_13

Fortunato $G$ et al (2017) Dependency of rubber friction on normal force or load: theory and experiment. Tire Sci Technol 45(1):25-54. https://doi.org/10.2346/tire.17.450103

Geim A (2009) Graphene: status and prospects. Science 324(5934):1530-1534. https://doi.org/10.1126/science. 1158877

Harea E, Stoček R, Machovský M (2017) Study of friction and wear of thermoplastic vulcanizates: the correlation with abraded surfaces topology. J Phys Conf Ser 843:012070. https://doi.org/10.1088/1742-6596/843/1/012070

Hentour K et al (2016) Carbon nanotube/alumina and graphite/alumina composite coatings on stainless steel for tribological applications. Mater Today Commun 8:118-126. https://doi.org/10.1016/j.mtcomm.2016.07.007

Hwang S, Park YB et al. (2011) Smart materials and structures based on carbon nanotube composites. In: Yellampalli S (ed) Carbon nanotubes-synthesis, characterization, applications. InTech, Rijeka, pp 371-396. https://doi.org/10.5772/17374

Iijima S (1991) Helical microtubules of graphitic carbon. Nature 354:56-58. https://doi.org/10.1038/354056a0

Kroto HW, Heath JR et al (1985) C60: Buckminsterfullerene. Nature 318:162163. https://doi.org/10.1038/318162a0

Ma PC et al (2008) Effect of CNT decoration with silver nanoparticles on electrical conductivity of CNT-polymer composites. Carbon 46(11):1497-1505. https://doi.org/10.1016/j.carbon.2008.06.048 
Maegawa S, Itoigawa F, Nakamura T (2016) Dynamics in sliding friction of soft adhesive elastomer: Schallamach waves as a stress-relaxation mechanism. Tribol Int 96:23-30. https://doi.org/10.1016/j.triboint.2015.11.034

Nakaramontri Y et al (2015) The effect of surface functionalization of carbon nanotubes on properties of natural rubber/carbon nanotube composites. Polym Compos 36(11):2113-2122. https://doi.org/10.1002/pc.23122

Nakaramontri Y et al (2017) Hybrid carbon nanotubes and conductive carbon black in natural rubber composites to enhance electrical conductivity by reducing gaps separating carbon nanotube encapsulates. Eur Polym J 90:467484. https://doi.org/10.1016/j.eurpolymj.2017.03.029

Nuruzzaman D, Chowdhury M (2012) Effect of Load and sliding velocity on friction coefficient of aluminum sliding against different pin materials. Am J Mater Sci 2(1):26-31. https://doi.org/10.5923/j.materials.20120201.05

Reinert L et al (2016) Tribo-Mechanisms of carbon nanotubes: friction and wear behavior of CNT-reinforced nickel matrix composites and CNT-coated bulk nickel. Lubricants 4(11):1-15. https://doi.org/10.3390/lubricants4020011

Schallamach (1952) The Load dependence of rubber friction. Proc Phys Soc B 65(9):657-661

Subramaniam K et al (2013) Elastomer composites based on carbon nanotubes and ionic liquid. Compos Rubber Chem Technol 86(3):367-400. https://doi.org/10.5254/rct.13.86984

Tegtmeier K et al (2016) Residual rubber shielded multi walled carbon nanotube electrodes for neural interfacing in active medical implants. Phys Med 1:8-19. https://doi.org/10.1016/j.phmed.2016.04.001

Yanchenko VV, Sementsov Y, Melezhyk AV (2004) Method of obtaining of carbon nanotubes. Pat. 69292 A UA, C01B 31/00/-16.08.04 